\title{
The Single Ventricle Reconstruction Trial: The data goes public
}

\author{
Scott M. Bradley, MD
}

\author{
From the Department of Pediatric Cardiac Surgery, Medical University of South Carolina, Charleston, SC. \\ Disclosures: Author has nothing to disclose with regard to commercial support. \\ Received for publication April 22, 2016; accepted for publication April 26, 2016. \\ Address for reprints: Scott M. Bradley, MD, Pediatric Cardiac Surgery, Medical University of South Carolina, \\ CSB 42496 Jonathan Lucas St, Charleston, SC 29425 (E-mail: bradlesm@musc.edu). \\ J Thorac Cardiovasc Surg 2016;152:195-6 \\ $0022-5223 / \$ 36.00$ \\ Copyright (c) 2016 by The American Association for Thoracic Surgery \\ http://dx.doi.org/10.1016/j.jtcvs.2016.04.074
}

The Single Ventricle Reconstruction (SVR) Trial has arguably been the most productive study in congenital heart surgery. The trial, conducted by the Pediatric Heart Network, enrolled 549 neonates undergoing a Norwood procedure across 15 centers between 2005 and 2008. ${ }^{1}$ The patients were prospectively randomly assigned to undergo either a modified Blalock-Taussig shunt or a right ventricle-to-pulmonary artery shunt. To date, SVR writing groups have published no fewer than 30 articles on the primary and secondary outcomes of this trial. ${ }^{2}$ After the initial SVR Surgical Trial, the Single Ventricle Extension Study (SVR II) examined the SVR cohort at 2 to 6 years of age. ${ }^{3}$ The SVR Long Term Followup Study (SVR III), currently underway, is examining these patients at 10 to 12 years of age. The SVR Trial data have shaped our thinking about shunt selection as well as a range of outcomes for babies born with hypoplastic left heart syndrome. The designers of the SVR Trial had the vision to realize that this patient cohort would be leveraged to yield important information for many years. ${ }^{4}$

In March 2014, the data from the SVR Trial were made public, enabling another tier of studies from the trial. There are currently roughly 80 registered users of the public data set. In this issue of The Journal, Mah and colleagues ${ }^{5}$ from Boston Children's Hospital have used the data set to examine the incidence and effects of heart block after stage 1 single-ventricle palliation. Although this is a highly focused topic, it is also one that has not previously been closely examined. The study's primary findings are in accord with clinical intuition: heart block in this setting is rare, but when it does occur, it portends a poor prognosis. The incidence of heart block within the first year of life was $6 \%$ (33/549 patients). Most cases (76\%) occurred within 1 week of surgery, either stage 1 or stage 2 palliation. Independent risk factors for heart block were tricuspid valve repair during stage 1 , and pre-stage 1 intervention for pulmonary venous obstruction. The occurrence of heart block led to a markedly lower transplantation-free survival at 3 years $(39 \%$ vs $65 \%)$. Of note, heart block was as strong a predictor of poor outcome as were other wellcharacterized risk factors, including presence of a genetic

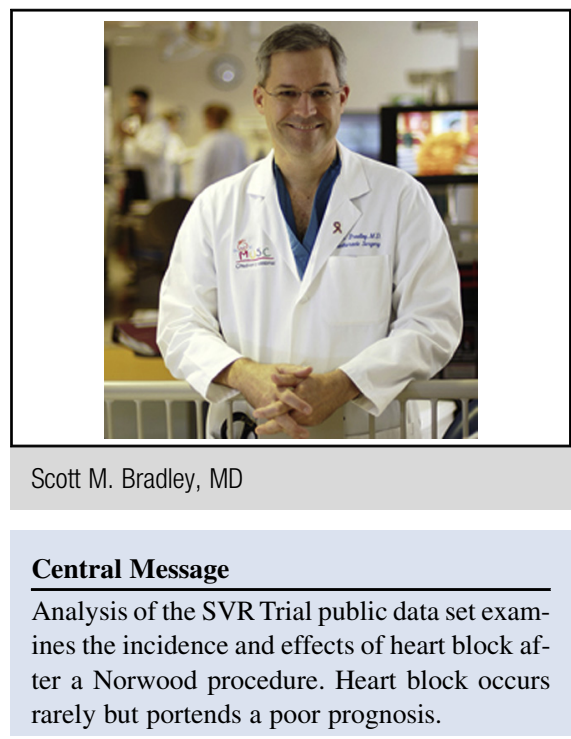

See Article page 189.

syndrome, need for intraoperative extracorporeal membrane oxygenation, obstructed pulmonary venous drainage, and low birth weight. Among the 33 patients with heart block, pacemakers were implanted in only 9 patients, 7 of whom subsequently died or underwent a transplant. This suggests that pacemaker placement did not neutralize the risk added by the development of heart block, although it may have bridged some patients to transplant. Mah and colleagues $^{5}$ are to be commended for continuing to mine the SVR data set for this important information.

Heart block after stage 1 palliation could have several etiologies. Atrioventricular node trauma could occur during surgical atrial septectomy, tricuspid valve repair, or cardiac catheterization, either diagnostic or interventional. Another potential source of trauma is the atrial cannula used during surgery. Alternatively, myocardial ischemia as a result of poor myocardial protection or compromised coronary perfusion could result in heart block. The 2 risk factors for heart block identified in this study are in support of direct trauma as an etiology; among the 33 patients with heart block, however, only 3 underwent pre-stage 1 intervention for pulmonary venous obstruction, 5 underwent tricuspid valve repair at stage 1 , and 6 underwent tricuspid valve repair at stage 2 , so other causes were in play in the majority of cases.

The information in the SVR data set regarding heart block has several significant limitations. The SVR data 
forms include a single selection for "atrioventricular block (second or third degree)," so that no distinction can be made between second-degree and complete heart block. Several other questions of interest cannot be addressed. Was the heart block transient or permanent? What was its duration? What were the details of pacemaker lead placement? What happened to the 22 patients with heart block who did not have a pacemaker placed? Did cardiac catheterization after stage 1 palliation play a role in some cases? These limitations and unanswered questions could direct future inquiry into the role of heart block in staged palliation for hypoplastic left heart syndrome. This would be facilitated by a data set containing both granular data on heart block and long-term outcome data, which might require linkage among existing databases. For example, in its current form, the Pediatric Cardiac Critical Care Consortium Registry contains some of the data necessary for accurate identification of perioperative heart block, including start date, duration, and need for temporary or permanent pacing. ${ }^{6}$ The Pediatric Cardiac Critical Care Consortium is focused on the intensive care unit course, however, so could be linked to a registry containing long-term outcomes, such as the Congenital Heart Surgeons' Society database. This type of database linkage is currently being undertaken for the Society of Thoracic Surgeons Congenital
Heart Surgery Database and the Congenital Heart Surgeons' Society database. ${ }^{7}$ A study within a linked registry may provide the best look at this topic, as well as at other complications that occur infrequently.

\section{References}

1. Ohye RG, Sleeper LA, Mahony L, Newburger JW, Pearson GD, Lu M, et al; Pediatric Heart Network Investigators. Comparison of shunt types in the Norwood procedure for single-ventricle lesions. N Engl J Med. 2010;362:1980-92.

2. Pediatric Heart Network. The Pediatric Heart Network. Available at: http://www. pediatricheartnetwork.org. Accessed April 15, 2016.

3. Newburger JW, Sleeper AL, Frommelt PC, Pearson G, Mahle WT, Chen S, et al; Pediatric Heart Network Investigators. Transplantation-free survival and interventions at 3 years in the Single Ventricle Reconstruction Trial. Circulation. 2014;129:2013-20.

4. Ohye RG, Gaynor JW, Ghanayem NS, Goldberg CS, Laussen PC, Frommelt PC, et al; Pediatric Heart Network Investigators. Design and rationale of a randomized trial comparing the Blalock-Taussig and right ventricle-pulmonary artery shunts in the Norwood procedure. J Thorac Cardiovasc Surg. 2008;136:968-75.

5. Mah DY, Cheung H, Alexander ME, Sleeper L, Newburger JW, del Nido PJ, et al. Heart block following stage 1 palliation of hypoplastic left heart syndrome J Thorac Cardiovasc Surg. 2016;152:189-94.

6. Gaies M, Cooper DS, Tabbutt S, Schwartz SM, Ghanayem N, Chanani NK, et al. Collaborative quality improvement in the cardiac intensive care unit: development of the Paediatric Cardiac Critical Care Consortium (PC4). Cardiol Young. 2015; 25:951-7.

7. Jacobs JP, Pasquali SK, Austin E, Gaynor JW, Backer C, Hirsch-Romano JC, et al. Linking the congenital heart surgery databases of the Society of Thoracic Surgeons and the Congenital Heart Surgeons' Society: part 1-rationale and methodology. World J Pediatr Congenit Heart Surg. 2014;5:256-71. 